These observations, culled from the treatise under notice, are suffcient to indicate the distinctive and most common diseases of miners, and will serve to recommend its study to those especially who are occupied in their profession in mining districts. The peculiar lesion of the lung in miner's consumption well deserves a minute inquiry, for we have no doubt whatever that the majority of cases of this disease are looked upon and registered as cases of tubercular phthisis.

\title{
Review XIII.
}

\section{Consumption: its Early and Remediable Stages. By Edward Smith,} M.D., LL.B., F.R.S., A ssistant-Physician to the Hospital for Consumption and Diseases of the Chest, Brompton, \&c.-London, 1862. pp. 447.

THIs is a great theme, and as obscure as it is important. In the work the title of which is prefixed, it has been ably discussed by Dr. Edward Smith, who, with a large experience of the disease in its fully developed form, has brought to the study of it in its early insidious, and, as we think, its latent stage, such aids as an advanced physiology and pathology afford, and especially the results of his own physiological researches.

He states in his preface that in undertaking the work, he has had-

"Four principal objects in view-viz., to take advantage of the growing belief of the day that there is a stage of phthisis in which the disease is as remediable as it is irremediable at a later period; to write a practical work in which may be faithfully represented the actual conditions of those cases when regarded in the great numbers in which they have been brought before his observation; to treat the subject, as far as possible, on the inductive method, and on the improved physiology and pathology of the day; and to give practical effect to numerous series of special inquiries, which have been made by him during the preceding seven years."

In his prolegomena, he gives a brief historical sketch of the views which have been entertained of phthisis from the time of Hippocrates to the present period, including the opinions of his contemporaries, of those mainly who agree with him that phthisis has an eariy stage before the development of tubercle, and that tubercle is not its prime cause, but rather its epigenesis; and that in this its early stage it is recognisable and curable. Such is the pith of his great argument. Whilst, however, holding this doctrine, he liberally admits that there are still those, and distinguished pathologists, who advocate the doctrine to which he is opposed-viz., that tubercle, in the chain of causation, is the first that is admissible; that without it the disease does not exist; and, consequently, if curable, it is by the arresting of the production of tubercle, and the preventing of their renewal.

The authorities he quotes in favour of his own views are Sir James Clark, to whom the work is dedicated, Dr. Hughes Bennett, Dr. Hamilton Roe, Dr. Richard Quain, Dr. Cotton, Mr. Ancell, and especially Dr. Lawson. On the opinion of the last he lays much stress, as it so nearly accords with his own, which he states he had 
promulgated seven years before that of the American pathologist had been published. Dr. Lawson, treating of a precursory stage, describes it as "a morbid state existing intermediately between the mere diathesis on the one hand, and the deposit of solid tubercles in the lungs on the other." He defines diathesis to be "a constitutional predisposition to disease which, under favourable circumstances, may never become developed;" whilst "the precursory stage, on the contrary, is the beginning of a positive morbid action which, if not arrested, surely and steadily progresses to the deposit of tubercles." *

We dwell rather on this first portion of Dr. Smith's work, inasmuch as it contains the doctrinal principle on which all that follows may be said to depend. As to the manner in which he supports this doctrine of a precursory, recognisable, curable stage or "stages" of the disease, a degree of credit is due to him; and although we cannot say that he has made us entirely converts to his special views, we are ready to admit that he has rendered them specious, and put them in such a light as to be deserving of our attention.

The subject, we think, must be admitted to be, like the prodroma of so many other diseases, of great difficulty and obscurity, and hardly permitting of demonstration, which is indeed allowed by the author. What are the principal indications of this early stage? They are, as laid down by him, chiefly the following. We shall quote his words; and they are all given with emphasis in italics:

“The appetite seldom remains natural, but is somewhat lessened in respect. of food in general, and of some foods in particular, and commonly wayward and uncertain."

"There is commonly some derangement of the function of digestion, but it is frequently small, and in such cases is not important."

"The amount of food taken is commonly somewhat lessened."

"The assimilation of food is commonly defective."

"The weight and bulk of the body are almost universally lessened."

"The fixation of fluid in the body is lessened, and the elimination of it increased."

"The action of the skin is commonly increased, either absolutely or relatively to the vital transformation."

"The amount of urine evolved is perhaps equal to that in health, but varies with the activity of the other outlets of the body."

"Perspirations are common in the early, as in the later stages of phthisis, and oftentimes have a sour odour."

"There is a general tendency to defects of temperature of the body."

"The muscular power is commonly lessened."

"The circulation is commonly enfeebled and somewhat quickened."

"The respiration is shorter, shallower, feebler, and perhaps quicker."

"The vital capacity of the lungs is diminished even when there are no evidences whatever of the presence of tubercular deposits."

"Innervation is commonly lessened."

"The menstrual function is frequently disturbed, but probably not in a greater degree than occurs in health. There is much liability to leucorrhœa."

"Muscular pains about the chest are very common."

* We hope shortly to present our readers with a notice of Dr. Lawson's work, entitled, 'A Practical Treatise on Phthisis Pulmonalis ; embracing its Pathology, Causes, Syıntoms, and Treatment.' Cincinnati, 1861. 
"The form of the throat in phthisis is peculiar, and differs much from that seen in chronic bronchitis."

"There is commonly only a small or moderate amount of coughing."

"There is commonly a small amount of expectoration."

"In the majority of cases there has been hæmoptysis in some degree, but not necessarily proceeding from the lungs."

"A tendency to vomiting not unfrequently occurs."

These aphorismal propositions are minutely and ingeniously discussed. Considered individually, it seems to us that for most part little reliance can be placed on them as indicating, what they are supposed by Dr. Smith to show, the premonitory or precursory curable stage of phthisis, inasmuch as no one of them is pathognomonic, inasmuch as any one of them may be connected with an ephemeral derangement of health, or be the precursor of some pending malady totally distinct from tuberculosis. Taken as a whole, they may indeed tolerably designate an early stage of phthisis, but we cannot venture to say the premonitory curable stage. We write thus reservedly, from the belief that the symptoms expressed in the several aphorisms are of unequal value, and likewise from labouring under the uncertainty that they all belong to the same stage of the disease, especially the first and the last mentioned-the last, such as the hæmoptysis and vomiting, particularly the hæmoptysis-that, we think, being rather a sign of pre-existing tubercle.

Independently of the doubts we have of the possibility of recognising phthisis in its presumed earliest stage, from the vagueness of the symptoms laid down, we have another ground for hesitation in adopting our author's conclusions-viz., our belief that tubercles may exist in the lungs, and be even somewhat advanced, without materially deranging the general health-without at least occasioning any symptom to excite attention, either of the individual affected or of his friends, so as to call for medical advice and treatment.

The doctrine advocated by Dr. Smith we necessarily, after what we have said, hold to be, as regards ordinary practice, of less value than he attaches to it; and, indeed, not altogether free from the danger of abuse - that is, from the unscrupulous few, and from the little reflecting many, who exercise the medical profession. It may be said, and most truly, that the treatment propounded in accordance with the doctrine is such as is safe, even though there be an error of prognosis. The treatment proposed by Dr. Smith being of the tonic, invigorating kind, conducive every way, and on the soundest principles, to the improvement of the general health. Granted all this, yet how serious would be the alarm excited by the announcement of a threatening consumption, and how firm would be the hold on the patient by the practitioner, on his declaring, that if not timely taken, a fatal disease must be the issue.

As bearing on the subject of phthisis generally, irrespective of its early stage, the last chapter of the work, containing the analysis of 1000 cases of the confirmed disease, is specially deserving of attention; and to us the results arrived at are confirmatory of the opinion we 
have expressed of the comparatively little value of those indications which are assigned as premonitory.

The first result of Dr. Smith's analysis is, that phthisical patients are of no one condition, but are of a mixed class of the community, in accordance with all former experience. Also, in accordance with this experience, that the age of the largest proportion of the victims of the disease is, between twenty and thirty years; only thirteen per cent. having been under twenty years, and only a few having attained sixty years. In relation to dress, that of the whole number only 25 per cent. had never worn flannel. In relation to marriage, that 43.5 per cent. were in that state, of whom 13 per cent. were childless. Lastly, in relation to bad habits and unwholesome occupations, that " 11.6 per cent. had committed sexual abuse, 18.2 per cent. had masturbated, 22 per cent. had suffered from involuntary emissions, 16 per cent. had had syphilis, and 38.5 per cent. had had gonorrhœa; 29.6 per cent. had led a bad life at some period, 24.5 per cent. had drunk to excess, and 48 per cent. had smoked tobacco; $19 \cdot 3$ per cent. had submitted to late hours, and $22 \cdot 2$ per cent. had suffered much anxiety." And that in 70 per cent. there was some complaint as to the injurious influence of their occupations; and of these as causes, exposure, long hours, close and hot rooms, bending posture, and dust or fumes were complained of in $32 \cdot 1,28 \cdot 6,24 \cdot 4,20$, and $15 \cdot 8$ per cent. in their order." Further, that " 9 per cent. had taken mercury largely, and 54 per cent. had been bled at the arm from one to twelve times." Thus (he sums up) a large proportion of the patients had been born feeble, had had feeble and short-lived children, had suffered from the effects of injurious occupations, and had been injured by the anxieties and immoralities of life. These circumstances, he justly remarks, 'require to be taken into account, both in relation to the treatment to be employed, and the prognosis to be formed as to the probable curability of the disease, on the supposition that one or more of them have taken effect and have been concerned in the production of the disease $a b$ initio.

Our restricted limits barely allow us to notice in the briefest manner the other portions of Dr. Smith's work, those parts of it which relate to the etiology, pathology, and treatment of the disease; in which he fully keeps his promise of following the inductive method of inquiry, and of giving practical effect to the latest results of scientific research in any way bearing on the correction of the presumed malady.

We must not conclude our too brief notice of this work without strongly recommending its perusal, satisfied as we are, that though it may not doctrinally carry conviction to the mind of the reader, yet it cannot fail to give a great variety of information, and of an important kind, both on healthy and diseased functions, as illustrated by the author's own researches; and on various remedial means and particular medicines, embodying his own experience; and on other cognate matters, including climate. The value of the book for reference is enhanced by an ample table of well-arranged contents, and by a copious and useful index. 